\title{
ANÁLISE ECONÔMICA DE MILHO CONVENCIONAL E TRANSGÊNICO EM DOIS SISTEMAS DE PREPAROS DE SOLO
}

Doi:http://dx.doi.org/10.1590/1809-4430-Eng.Agric.v35n6p 1032-1041/2015

\section{PAULO R. A. SILVA ${ }^{1}$, TIAGO P. DA S. CORREIA ${ }^{2}$, SAULO F. G. DE SOUSA ${ }^{3}$, THAIS M. MILLANI ${ }^{4}$}

\begin{abstract}
RESUMO: O milho é um produto de grande importância na agricultura, em função de sua ampla utilização e das formas de produção. Tendo em vista esses cenários, o trabalho teve como objetivo a análise econômica do sistema de produção de milho utilizando diferentes híbridos de milho e preparos de solo. O estudo foi realizado na Fazenda Experimental Lageado, pertencente à Faculdade de Ciências Agronômicas/UNESP de Botucatu-SP. Foram analisados dois híbridos em dois tipos de sistemas de preparo do solo, sendo milho convencional e milho transgênico, em preparo convencional e cultivo mínimo. Para os diferentes tipos de cultivo, foram utilizados os mesmos tratores, implementos e adubação, sendo os seguintes parâmetros analisados: custos operacionais, custos de insumos, renda bruta, renda líquida e relação benefício/custo dos sistemas de cultivo. Conclui-se que a utilização de milho trans gênico proporciona redução dos custos operacionais e com insumos, possibilitando, em preparo de cultivo mínimo do solo, maior produtividade, renda líquida e relação benefício/custo.
\end{abstract}

PALAVRAS-CHAVE: custo operacional, produtividade, biotec nologia.

\section{ECONOMIC ANALYSIS OF CONVENTIONAL AND TRANSGENIC CORN UNDER TWO SOIL TILLAGE SYSTEMS}

\begin{abstract}
Corn is an agricultural crop of major importance regarding its wide use and production forms. Given these background, this work aimed at analyzing economically the corn production chain with different hybrids and soil tillage systems. The study was carried out at the Experimental Farm of Lageado, located in the College of Agricultural Sciences/ UNESP, campus in Botucatu-SP, Brazil. We analyzed two corn hybrids, one conventional and another transgenic, on soil prepared by conventional cultivation practices and minimum cultivation. The same tractors, implements, and fertilizers were employed for both tillage systems. We evaluated operating costs, input costs, gross income, net income, as well as benefit and cost ratio of both cropping systems. Therefore, we concluded that transgenic corn provides reduced operating costs and inputs, enabling higher yield, net income and benefit/cost relationship when cropped with minimum cultivation practices.
\end{abstract}

KEYWORDS: operational cost, yield, biotechnology.

\section{INTRODUÇÃO}

A cultura do milho representa o principal produto da base alimentar de vários países, sendo utilizado principalmente para produção de ração animal. Por sua importância e amplo aspecto de utilização, atualmente, o milho é o cereal mais cultivado no mundo (DEMARCHI, 2012). No Brasil, para a safra 2012/2013, foram cultivados 15,7 milhões de hectares da cultura, obtendo-se a produção de aproximadamente 78 milhões de toneladas (CONAB, 2013).

\footnotetext{
${ }^{1}$ Eng. A grônomo, Prof. Doutor, Departamento de Engenharia Rural, FCA-UNESP/Botucatu - SP, (14) 3811-7127, arbex@fca.unesp.br

${ }^{2}$ Eng. Agrônomo, Doutor em A gronomia, Departamento de Engenharia Rural, FCA-UNESP/Botucatu - SP, correiagoueg@hotmail.com

${ }^{3}$ Eng. A grônomo, Doutorando, Departamento de Engenharia Rural, FCA-UNESP/Botucatu - SP, saulo@ fca.unesp.br

${ }^{4}$ Eng $^{\circ}$ Florestal, Mestre em Agronomia, FCA-UNESP/Botucatu - SP, 
Os avanços tecnológicos em melhoramento genético agregam à cultura do milho, grande potencial produtivo, destacando-se no Brasil a biotecnologia das sementes transgênicas resistentes a insetos e tolerantes a herbicidas, ou a combinação de ambas (MIGUEL et al., 2014). Como reflexo da maior resistência da planta ao ataque de insetos, é verificado o crescimento na produtividade de grãos (SILVEIRA, 2005).

Mesmo com toda evolução tecnológica embutida nas sementes dos híbridos de milho, a produtividade média brasileira encontra-se em $4961 \mathrm{~kg} \mathrm{ha}^{-1}$, segundo levantamento realizado pela CONAB (2013). Tal situação exige estratégias de manejo que possam incrementar a produtividade, sendo importante neste sentido o sistema de preparo do solo (PORTELA et al., 2014; ROCHA et al., 2014).

De acordo com CUNHA et al. (2011), os sistemas de preparo do solo mais utilizados são o preparo convencional, o cultivo mínimo ou reduzido e o plantio direto. O preparo convencional do solo é caracterizado por sua mobilização intensiva na camada arável, aumentando a possibilidade de translocação de argila no perfil, a compactação do solo, as erosões e a oxidação da matéria orgânica (ANDRADE et al., 2009). Por cultivo mínimo do solo entende-se o uso de escarificadores ou subsoladores para o rompimento de camadas compactadas e a manutenção de cobertura vegetal sobre o solo, sendo uma alternativa de manejo conservacionista do solo em relação ao preparo convencional (FUENTES-LLANILLO et al., 2013).

Em relação à produtividade de milho, deve-se levar em conta não apenas a tecnologia genética dos hibridos e o sistema de preparo do solo, mas também a eficiência das máquinas e implementos que estão sendo utilizados no preparo do solo e demais operações envolvidas no processo produtivo (ALMEIDA et al., 2010).

CENTENO \& KAERCHER (2010) relatam que os custos referentes à mecanização das operações agrícolas, nas diferentes culturas, representam entre 10 e $30 \%$ dos custos totais de produção, demonstrando a importância da escolha do maquinário mais adequado para o processo produtivo. Os custos operacionais, segundo MILAN (2004), é a relação entre o custo horário da máquina, ou conjunto mecanizado, e sua capacidade de trabalho.

Admitindo que híbridos trans gênicos de milho possuem maior valor agregado nas sementes, e que os diferentes sistemas de preparo do solo necessitam de diferentes operações mecanizadas, é relevante verificar a viabilidade econômica desses dois fatores associados. Desta forma, o presente trabalho teve como objetivo analisar a viabilidade econômica de milho transgênico e convencional em sistema de preparo do solo convencional e mínimo, quantificando os custos totais com máquinas e insumos, a produtividade de grãos, a renda bruta e a renda líquida relacionada.

\section{MATERIAL E MÉTODOS}

O trabalho foi conduzido no ano agrícola de 2009/2010, na Fazenda Experimental Lageado, pertencente à Faculdade de Ciências Agronômicas - UNESP de Botucatu - SP.

Os tratamentos foram compostos por dois sistemas de preparo do solo (cultivo mínimo e preparo convencional), e dois tipos de híbridos de milho, um transgênico e outro não transgênico. As sementes utilizadas foram do híbrido convencional 2B604 e de seu isogênico 2B604Hx, transgênico ao ataque da lagarta-do-cartucho (Spodoptera frugiperda). Para adubação de base, foram utilizados $300 \mathrm{~kg} \mathrm{ha}^{-1}$ do formulado NPK 8-28-16, e na adubação em cobertura, $200 \mathrm{~kg} \mathrm{ha}^{-1}$ de ureia, conforme recomendado na análise de solo.

O solo da área experimental é classificado, conforme EMBRAPA (1999), como Nitossolo Vermelho distroférrico, contendo aproximadamente 425; 202 e 375 g. $\mathrm{kg}^{-1}$ de areia, silte e argila respectivamente. Seu histórico é caracterizado pelo cultivo de soja (Glycine max L. Merril) e aveia-preta (Avena strigosa Schreb), destinada à manutenção e à formação de palhada. Além de restos culturais de soja e aveia-preta, o solo apresentava vegetação espontânea de capim-colonião (Panicum-maximum Jacq), capim-gordura (Melinis minutiflora Beauv), buva (Conyza bonariensis), 
picão-preto (Bidens pilosa) e capim-carrapicho (Cenchrus echinatus). Pelo método de LAFLEN et al. (1981), foi determinada a quantidade média de 8,2 t.ha ${ }^{-1}$ de matéria seca na área experimental.

Para a realização dos preparos do solo, semeadura e determinação de consumo de combustível, foi utilizado o trator marca John Deere, modelo JD6600 4x2 TDA, com potência de 88,9 kW no motor. Para a realização da adubação em cobertura e das pulverizações, foi utilizado o trator marca Massey Ferguson, modelo MF283 4x2 TDA com potência de 63,2 kW no motor. No preparo de solo no sistema cultivo mínimo, foi utilizado um escarificador de arrasto marca Jan, modelo JMAD-7, equipado com sete has tes parabólicas espaçadas em 0,40 m, largura das ponteiras de $0,08 \mathrm{~m}$ e massa total de $1400 \mathrm{~kg}$, conforme indicado pelo fabricante. A profundidade de trabalho utilizada foi de $0,20 \mathrm{~m}$, determinada a partir da verificação de resistência do solo à penetração, conforme ind icam TIEPPO et al. (2011), STOLF et al. (2012) e MOLIN et al. (2012), realizada com auxílio de um penetrômetro analó gico marca Soilcontrol, modelo Compact-test, equipado com haste de $0,70 \mathrm{~m}$.

No preparo convencional do solo, foram realizadas duas gradagens, uma com grade intermediária modelo GAICR com 20 discos recortados, espaçados em $0,27 \mathrm{~m}, 28$ polegadas de diâmetro, largura de corte de $2,57 \mathrm{~m}$ e massa total de $2272 \mathrm{~kg}$, e outra com grade niveladora modelo GNL com 32 discos lisos, espaçados em $0,17 \mathrm{~m}, 20$ polegadas de diâmetro, largura de corte de 2,55 $\mathrm{m}$ e massa total de $725 \mathrm{~kg}$. A semeadura dos híbridos foi realizada com semeadora-adubadora marca Tatu, modelo PS6, com quatro linhas espaçadas de $0,85 \mathrm{~m}$.

O pulverizador utilizado nas aplicações de herbicidas e inseticidas foi da marca Jacto, modelo Falcon Vortex, com capacidade de $600 \mathrm{~L}$ e barra de $12 \mathrm{~m}$. O cultivador utilizado na adubação de cobertura constava de quatro linhas espaçadas de $0,9 \mathrm{~m}$. Para a colheita, foi utilizada a colhedora marca Massey Ferguson, modelo MF3640 com 88,3 kW de potência no motor, plataforma de colheita com 3,6 m de largura e reservatório graneleiro com capacidade de $2100 \mathrm{~kg}$.

A velocidade efetiva de trabalho de cada operação foi verificada a partir do tempo necessário para deslocamento nas parcelas, sendo registrado com auxílio do painel de instrumentos eletrônicos do tipo "MICRO-P".

A capacidade de campo efetiva (Cce) das máquinas foi determinada através da [eq. (1)].

$\mathrm{Cce}=(\operatorname{Aup} / \Delta \mathrm{t}) \cdot 0,36$

em que,

Cce - capacidade de campo efetiva $\left(\mathrm{ha} \mathrm{h}^{-1}\right)$;

Aup - área útil da parcela trabalhada $\left(\mathrm{m}^{2}\right)$;

$\Delta \mathrm{t}$ - tempo gasto para percorrer a parcela $(\mathrm{s})$,

0,36 - fator de conversão de $\mathrm{m}^{2} \mathrm{~s}^{-1}$ para ha $\mathrm{h}^{-1}$;

Foram utilizados os seguintes defensivos agrícolas para a condução do trabalho: uma aplicação do herbicida Atrazine $500 \mathrm{SC}$, na dose de 3,0 $\mathrm{L} \mathrm{ha}^{-1}$; uma aplicação de herbicida pós-emergente Nicosulfuron $40 \mathrm{SC}$, na dose de $0,4 \mathrm{~L} \mathrm{ha}^{-1}$ e uma aplicação do inseticida Espinosade, dose de $0,06 \mathrm{~L} \mathrm{ha}^{-1}$, para o controle da lagarta-do-cartucho nos tratamentos com milho não transgênico.

O custo operacional das máquinas foi determinado conforme metodologia da American Society of Agricultural and Biological Engineers (ASABE, 2006), sendo este dividido em custos fixos e variáveis, considerando-se juros, depreciação, fator de alojamento, manutenção e mão de obra. As equações utilizadas para os cálculos são enumeradas e descritas conforme a Tabela 1. 
TABELA 1. Equações para o cálculo do custo com máquinas agrícolas pela metodologia ASABE (2006). Equations used for calculating farm machinery costs based on method proposed by ASABE (2006).

\begin{tabular}{|c|c|}
\hline $\mathrm{N}^{\circ}$ da equação & Equação \\
\hline 1 & $\mathrm{~J}=[(\mathrm{Vi}+\mathrm{Vf}) / 2] .\left[\mathrm{Tj} \cdot(1+\mathrm{Tj})^{\mathrm{N}} /(1+\mathrm{Tj})^{\mathrm{N}}-1\right]$ \\
\hline 2 & $\mathrm{M}=\left[\mathrm{Vi} \cdot \mathrm{Fr}_{1} \cdot(\mathrm{h} / 100)^{\mathrm{Fr} 2}\right] / \mathrm{N}$ \\
\hline 3 & $\mathrm{CMO}=\mathrm{SM} .1,25 / \mathrm{NT}$ \\
\hline 4 & $\mathrm{CHC}=\mathrm{P}_{\mathrm{C}} \cdot(0,157 \cdot \mathrm{POT})$ \\
\hline 5 & $\mathrm{CHLG}=0,15 . \mathrm{CHC}$ \\
\hline 6 & $\mathrm{CV}=\mathrm{CHC}+\mathrm{CHLG}$ \\
\hline 7 & $\mathrm{CT}=\mathrm{D}+\mathrm{A}+\mathrm{S}+\mathrm{M}+\mathrm{CMO}+\mathrm{CV}$ \\
\hline
\end{tabular}

O custo com juro (1) foi determinado por meio do juro composto, valor inicial (Vi) e valor final (Vf) da máquina, sendo que o percentual da taxa de juro (Tj), foi estipulado em 5,5\%, conforme circular $n^{\circ}$ 31/2014 do BNDES (BNDES, 2014), incide também sobre os juros e o preço médio do bem. O custo de manutenção (2) considera o número de horas que a máquina foi utilizada $(\mathrm{N})$, além de coeficientes tabelados, denominados fatores de reparo 1 e 2 (Trator $-\mathrm{Fr} 1=0,003$ e $\operatorname{Fr} 2=2,0$; Semeadora $-\operatorname{Fr} 1=0,32$ e Fr2 = 2,1).

O custo horário com mão de obra CMO (3) foi calculado por meio do salário médio (SM), por hora, incluindo todas as despesas com encargos sociais, dividido pelo número de horas efetivamente trabalhadas (NT). Consideraram-se o tratorista e um funcionário recebendo salários de $\mathrm{R} \$ 2000,00$ e R \$1000,00 ao mês, respectivamente, com acréscimo de $13^{\circ}$ salário, férias e INSS. Efetuou-se a conversão em custo horário de mão de obra, adotando-se jornada de trabalho de 8 horas diárias e 20 dias por mês.

Para operações agrícolas, consideram-se, entre os custos variáveis $(\mathrm{CV})$, o combustível, a graxa e os óleos lubrificantes. O consumo horário de combustível baseia-se no preço do combustível $\left(\mathrm{P}_{\mathrm{C}}\right)$ e no consumo horário, calculado pela potência do trator (POT), multiplicado pelo coeficiente de consumo específico de diesel por hora. Desta forma, o custo horário de combustível (CHC) foi calculado com a equação (4).

O custo horário com óleos lubrificantes e graxa (CHLG) foi calculado conforme a equação (5). A partir da equação (6), estimou-se o custo total variável (CV), e finalmente, pela equação (7), estimou-se o custo horário total (CT). Os custos com alojamento (A), depreciação (D) e seguro (S) foram obtidos conforme metodologia descrita por MIALHE (1974). A depreciação (D) foi calculada em horas pelo método linear, sendo o valor da máquina depreciado de um valor constante ao longo dos anos da vida útil, restando ao final o valor de sucata correspondente a $10 \%$ do $\mathrm{Vi}$ (BALASTREIRE, 2007). Os custos referentes ao seguro (S) e ao alojamento (A) foram obtidos conforme ASAE (2002), sendo $1 \%$ ao ano sobre o Vi de aquisição da máquina.

A relação benefício/custo nos diferentes sistemas de cultivo do milho foi calculada por meio da divisão da receita bruta pelo custo total com operações e insumos, conforme metodologia de SANTOS et al. (2008).

Os dados referentes às horas acumuladas de operação dos tratores e implementos, desde suas aquisições até a realização do trabalho, e quantidade de vezes que cada um deles foi utilizado nos diferentes cultivos, são apresentados na Tabela 2. 
TABELA 2. Características dos tratores e implementos, e quantidade de vezes em que foram utilizados no preparo convencional (PC) e cultivo mínimo (CM) do solo, utilizando milho convencional e trans gênico. Characteristics of the tractors and imple ments, and number of times they were used in soil conventional tillage (PC) and minimum tillage (CM) with conventional and transgenic corn.

\begin{tabular}{ccccccc}
\hline Trator/implemento & $\begin{array}{c}\text { Largura de trabalho } \\
(\mathrm{m})\end{array}$ & $\begin{array}{c}\text { Horas } \\
\text { Acumuladas }\end{array}$ & \multicolumn{2}{c}{$\begin{array}{c}\text { Milho } \\
\text { convencional }\end{array}$} & \multicolumn{2}{c}{$\begin{array}{c}\text { Milho } \\
\text { transgênico }\end{array}$} \\
\cline { 3 - 6 } & & 3000 & PC & CM & PC & CM \\
\hline Trator JD6600 & & 5000 & 4 & 4 & 2 & 2 \\
Trator MF283 & 2,57 & 3000 & 1 & 0 & 1 & 0 \\
Grade intermediária & 2,55 & 2500 & 1 & 0 & 1 & \\
Grade niveladora & 2,80 & 3000 & 0 & 1 & 0 & 1 \\
Escarificador & 14 & 7200 & 3 & 3 & 1 & 1 \\
Pulverizador & 3,40 & 5400 & 1 & 1 & 1 & 1 \\
Semeadora PS6 & 3,60 & 960 & 1 & 1 & 1 & 1 \\
Cultivador & 3,60 & 3000 & 1 & 1 & 1 & 1 \\
Colhedora MF3640 & & & & & & \\
\hline
\end{tabular}

PC: preparo convencional; CM: cultivo mínimo.

Os preços utilizados dos insumos foram consultados na cooperativa de produtores rurais Coopercitrus, e o preço do diesel foi considerado em $\mathrm{R} \$ 2,10 \mathrm{~L}^{-1}$, segundo ANP (2012). Os preços de aquisição das máquinas foram obtidos junto ao Anuário da Agricultura Brasileira de 2013 (AGRIANUAL, 2013), e o valor de venda da produção foi estabelecido em R $\$ 0,34 \mathrm{~kg}^{-1}$, conforme AOUN (2014).

As parcelas foram dimensionadas com $20 \mathrm{~m}$ de comprimento total e 3,6 $\mathrm{m}$ de largura total, espaçadas $15 \mathrm{~m}$ uma da outra para a realização das manobras necessárias e a estabilização do conjunto trator e implemento.

Somente para a determinação da produtividade de grãos $\left(\mathrm{kg} \mathrm{ha}^{-1}\right)$, foi considerada bordadura nas parcelas, sendo colhidas manualmente as espigas de todas as plantas presentes em $18 \mathrm{~m}$ de comprimento das duas linhas centrais de cada parcela. As espigas foram debulhadas por uma debulhadora estacionária de grãos, sendo posteriormente determinado o peso de cada parcela por meio de balança de precisão de 0,001 g. Após a pesagem, foi tomada uma amos tra de cada parcela e levadas ao laboratório para determinação da umidade da massa de grãos. As amostras foram pesadas e colocadas na estufa por 24 horas, a $105{ }^{\circ} \mathrm{C}$, sendo pesadas novamente, e a produtividade de grãos dada com correção para $13 \%$ de umidade.

O delineamento experimental foi o em blocos casualizados, com 4 tratamentos, sendo os fatores dois sistemas de preparo de solo e dois hibridos de milho, em esquema fatorial $2 \times 2$, com 4 repetições, formando um total de 16 parcelas experimentais (Figura 1). Os dados foram analisados por meio de estatística descritiva e comparação de médias. 


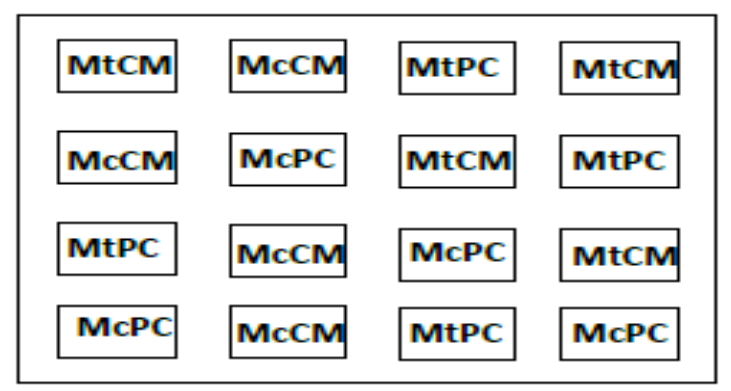

FIGURA 1. Croqui das parcelas experimentais, compostas por milho convencional em preparo convencional (McPC), milho convencional em cultivo mínimo (McCM), milho transgênico em preparo convencional (MtPC) e milho transgênico em cultivo mínimo (MtCM). Experimental plots sketching with conventional corn under conventional tillage (McPC), conventional corn under minimum tillage (McCM), transgenic corn under conventional tillage (MtPC), and transgenic corn under minimum tillage (MtCM).

\section{RESULTADOS E DISCUSSÃO}

Os resultados obtidos de velocidades de trabalho, capacidades de campo efetiva (Cce), consumo horário de combustível $(\mathrm{CCH})$ e consumo de combustível operacional $(\mathrm{CCO})$ são apresentados na Tabela 3.

TABELA 3. Médias da velocidade de trabalho, capacidade de campo específica (Cce), consumo de combustível horário $(\mathrm{CCH})$, consumo de combustível operacional $(\mathrm{CCO})$. Average working speed, specific field capacity (Cce), hourly fuel consumption $(\mathrm{CCH})$, operating fuel consumption ( $\mathrm{CCO})$.

\begin{tabular}{lcccc}
\hline \multicolumn{1}{c}{ Operação } & $\begin{array}{c}\text { Velocidade } \\
\left(\mathrm{km} \mathrm{h}^{-1}\right)\end{array}$ & $\begin{array}{c}\mathrm{Cce} \\
\left(\mathrm{ha} \mathrm{h}^{-1}\right)\end{array}$ & $\begin{array}{c}\mathrm{CCH} \\
\left(\mathrm{L} \mathrm{h}^{-1}\right)\end{array}$ & $\begin{array}{c}\mathrm{CCO} \\
\left(\mathrm{L} \mathrm{ha}^{-1}\right)\end{array}$ \\
\hline Escarificação & 4,10 & 0,91 & 14,15 & 15,56 \\
Gradagem intermediária & 4,36 & 0,89 & 10,89 & 12,24 \\
Gradagem niveladora & 7,2 & 1,69 & 9,66 & 5,72 \\
Semeadura no PC & 4,54 & 1,23 & 8,37 & 6,81 \\
Semeadura no CM & 4,58 & 1,24 & 7,83 & 6,32 \\
Adubação em cobertura & 6,4 & 1,84 & 17,27 & 9,39 \\
Pulverização & 5,21 & 5,83 & 6,81 & 1,16 \\
Colheita & 4,35 & 1,25 & 12,64 & 10,14 \\
\hline
\end{tabular}

Entre as operações realizadas, a escarificação apresentou maior CCO, com 15,56 L ha ${ }^{-1}$, que conforme cita BELLÉ et al. (2014), pode ser associado à profundidade de operação e à velocidade de trabalho do escarificador, fatores que determinam a força exigida na barra de tração e, por consequência, o maior consumo de combustível. O escarificador, dentre os demais implementos utilizados neste trabalho, foi o que trabalhou em maior profundidade, a $0,20 \mathrm{~m}$, corroborando o maior CCO. Porém, este consumo é menor que duas passadas da grade no preparo convencional, as quais somariam $24,48 \mathrm{~L} \mathrm{ha}^{-1}$.

O custo operacional das operações, apresentados na Tabela 4, indicam que, para ambos os tipos de materiais de milho utilizados, o preparo em cultivo mínimo apresentou menor custo operacional total que o preparo convencional. A utilização de gradagens no preparo convencional foi $50,3 \%$ mais onerosa que o custo da escarificação no cultivo mínimo. As operações de preparo do solo, gradagens e escarificação representam, respectivamente, 28,5 e 24,3\% do custo operacional do cultivo de milho convencional. Para o milho trans gênico essas operações representam 30,4 e 26\%. 
TABELA 4. Custo operacional das operações realizadas no cultivo do milho convencional e transgênico em preparo com cultivo mínimo (CM) e convencional (PC) do solo. Operational cost of conventional and transgenic corn cultivations under soil minimum tillage (CM) and conventional tillage (PC).

\begin{tabular}{lcccc}
\hline \multirow{2}{*}{ Operações } & \multicolumn{3}{c}{ Custo operacional (R $\$$ ha $^{-1}$ ) } \\
\cline { 2 - 5 } & \multicolumn{1}{c}{ Milho convencional } & \multicolumn{2}{c}{ Milho trans gênico } \\
\cline { 2 - 5 } & $\mathrm{CM}$ & $\mathrm{PC}$ & $\mathrm{CM}$ & PC \\
\hline Escarificação & 128,26 & -- & 128,26 & -- \\
Gradagem intermediária & -- & 129,15 & -- & 129,15 \\
Gradagem niveladora & & 30,28 & & 30,28 \\
Semeadura & 138,70 & 138,70 & 138,70 & 138,70 \\
Adubação de cobertura & 46,55 & 46,55 & 46,55 & 46,55 \\
Pulverização & 53,78 & 53,78 & 17,93 & 17,93 \\
Colheita & 160,35 & 160,35 & 160,35 & 160,35 \\
\hline \multicolumn{1}{c}{ Custo total operacional } & 527,64 & 558,81 & 491,79 & 522,96 \\
\hline PC: preparo convencional; CM: cultivo mínimo. & & & &
\end{tabular}

O tipo de híbrido de milho utilizado significou a diferença nos custos com pulverização. Para o milho transgênico, o custo com esta operação foi $66,6 \%$ menor que no convencional. A incidência da lagarta Spodoptera frugiperda no milho convencional torna neces sária a aplicação de inseticida por operação de pulverização, sendo realizadas mais vezes em relação ao milho transgênico, justificando seu maior custo com esta operação.

Custos com controle de Spodoptera frugiperda em milho transgênico e convencional foram estudados por MIGUEL et al. (2013), que descrevem que milho transgênico evidencia maior controle da lagarta sem necessidade de pulverizações e uso de inseticidas, havendo redução de $10 \%$ no custo operacional de produção do milho. Resultados semelhantes foram encontrados neste trabalho, com a redução na ordem de 7,2\% do custo operacional com milho trans gênico.

O milho transgênico no sistema de preparo de cultivo mínimo do solo apresentou menor custo operacional ( $\mathrm{R} \$ 491,79 \mathrm{ha}^{-1}$ ). O menor custo deste cultivo é justificado pelo menor número de pulverizações necessárias neste milho e pela não realização das operações de gradagens. Os custos operacionais encontrados são similares aos encontrados por JASPER et al. (2014), em torno de R\$ $400 \mathrm{ha}^{-1}$. Porém, MIGUEL et al. (2014) contabilizaram custo operacional maior, em torno de R\$ 1200,00 ha $\mathrm{h}^{-1}$, devido aos autores terem considerado no trabalho despesas com pós-colheita e administração.

Na Tabela 5 são demonstrados os custos com insumos utilizados no cultivo do milho, em que o maior custo foi encontrado para o milho convencional. A necessidade do uso de inseticida nestes tratamentos somou um custo de $\mathrm{R} \$ 133,56 \mathrm{ha}^{-1}$, representando $9,5 \%$ do custo no cultivo mínimo e 9,9\% no preparo convencional.

O maior custo com insumos foi verificado utilizando milho convencional no preparo em cultivo mínimo, devido ao uso de inseticida para controle da lagarta Spodoptera frugiperda e pela dessecação para preparo do solo com escarificador. O menor custo foi encontrado no milho transgênico em preparo convencional, não somando gastos com herbicida para dessecação e com inseticida. 
TABELA 5. Custos com insumos utilizados para cultivo de milho convencional e transgênico no preparo do cultivo mínimo e do convencional do solo. Costs of inputs used for conventional and transgenic corn under conventional tillage and minimum tillage.

\begin{tabular}{lcccc}
\hline \multirow{2}{*}{\multicolumn{1}{c}{ Insumos }} & \multicolumn{4}{c}{ Custo $\left(\mathrm{R} \$\right.$ ha $\left.^{-1}\right)$} \\
\cline { 2 - 5 } & \multicolumn{2}{c}{ Milho convencional } & \multicolumn{2}{c}{ Milho trans gênico } \\
\cline { 2 - 5 } & $\mathrm{CM}$ & $\mathrm{PC}$ & $\mathrm{CM}$ & $\mathrm{PC}$ \\
\hline Sementes & 340,00 & 340,00 & 420,00 & 420,00 \\
Adubo de plantio (NPK 8-28-16) & 432,00 & 432,00 & 432,00 & 432,00 \\
Adubo de cobertura (Ureia) & 256,00 & 256,00 & 256,00 & 256,00 \\
Herbicida Glifosato & 60,80 & -- & 60,80 & -- \\
Herbicida Atrazina & 124,17 & 124,17 & 124,17 & 124,17 \\
Herbicida Nicosulfuron & 51,50 & 51,50 & 51,50 & 51,50 \\
Inseticida Espinosade & 133,56 & 133,56 & -- & -- \\
\hline Custo total de insumos & 1398,03 & 1337,23 & 1344,47 & 1283,67 \\
\hline PC: preparo convencional; CM: cultivo mínimo. & & & &
\end{tabular}

A produtividade obtida nos diferentes cultivos permitiu os cálculos de renda bruta, renda líquida e relação benefício/custo dos diferentes cultivos. Conforme apresentados na Tabela 6, os resultados indicam maior produtividade obtida com milho trans gênico em cultivo mínimo, com $9676 \mathrm{~kg} \mathrm{ha}^{-1}$. Este mesmo sistema de cultivo apresentou menor custo total e proporcionou maior renda bruta, obtendo renda líquida de $\mathrm{R} \$ 1453,58 \mathrm{ha}^{-1}$.

TABELA 6. Produtividade média de milho convencional e transgênico em preparo convencional e mínimo do solo, renda bruta e líquida, e relação custo/benefício de cada tipo de cultivo. Average yield of conventional and transgenic corn under soil conventional tillage and minimum tillage, gross and net income, and cost and benefit relations hip of each cropping type.

\begin{tabular}{lcccc}
\hline \multirow{2}{*}{ Descrição } & \multicolumn{2}{c}{ Milho convencional } & \multicolumn{2}{c}{ Milho trans gênico } \\
\cline { 2 - 5 } & $\mathrm{CM}$ & PC & CM & PC \\
\hline Produtividade $\left(\mathrm{kg} \mathrm{ha}^{-1}\right)$ & 9.342 & 9.044 & 9.676 & 8.449 \\
Preço $\left(\mathrm{R} \$ \mathrm{~kg}^{-1}\right)$ & 0.34 & 0.34 & 0.34 & 0.34 \\
\hline Renda Bruta $\left(\mathrm{R} \$ \mathrm{ha}^{-1}\right)$ & 3176,28 & 3074,96 & 3289,84 & 2872,66 \\
\hline Custos & & & & \\
\hline Operacional $\left({\left.\mathrm{R} \$ \mathrm{ha}^{-1}\right)}^{\text {Insumos }\left(\mathrm{R} \$ \mathrm{ha}^{-1}\right)}\right.$ & 527,64 & 558,81 & 491,79 & 522,96 \\
\hline Total $\left(\mathrm{R} \$ \mathrm{ha}^{-1}\right)$ & 1398,03 & 1337,23 & 1344,47 & 1283,67 \\
\hline Renda líquida $\left(\mathrm{R} \$\right.$ ha $\left.^{-1}\right)$ & 1925,67 & 1896,04 & 1836,26 & 1806,63 \\
\hline Relação benefício/custo & 1250,61 & 1178,92 & 1453,58 & 1066,03 \\
\hline PC: preparo convencional; CM: cultivo mínimo. & 1,64 & 1,62 & 1,79 & 1,59 \\
\hline
\end{tabular}

O menor resultado de produtividade foi obtido com milho transgênico em preparo convencional, correspondendo à renda bruta de $\mathrm{R} \$ 2872,66 \mathrm{ha}^{-1}$ e renda líquida de $\mathrm{R} \$ 1066,03 \mathrm{ha}^{-1}$. A diferença entre as rendas líquidas com milho transgênico nos dois sistemas de preparo do solo, foi de $26,6 \%$.

As produtividades obtidas, a renda bruta e a renda líquida foram maiores que as encontradas por ESPERANCINI et al. (2004). Em trabalho sobre a análise de rentabilidade e de risco na produção de milho de verão na região de Botucatu-SP, os autores encontraram produtividade média de $6600 \mathrm{~kg} \mathrm{ha}^{-1}$, considerando o preço de venda de $\mathrm{R} \$ 0,29 \mathrm{~kg}^{-1}$, contabilizaram renda bruta de $\mathrm{R} \$$ 1914,00 ha ${ }^{-1}$ e renda líquida de $\mathrm{R} \$ 590,78 \mathrm{ha}^{-1}$. 
A melhor relação benefício/custo foi verificada utilizando milho transgênico em cultivo mínimo. Embasado neste resultado e também no resultado de benefício/custo do milho convencional em cultivo mínimo, pode-se destacar que o preparo em cultivo mínimo do solo é um fator importante na obtenção de maior renda líquida com a cultura do milho, independentemente do tipo de milho utilizado. Esta discussão corrobora com FERNANDES et al. (2008), ao concluírem que o cultivo mínimo demanda menor consumo de combustível que o convencional, proporcionando menor custo energético.

\section{CONCLUSÕES}

Conclui-se que a utilização de milho transgênico proporciona redução dos custos operacionais e com insumos, possibilitando, em preparo do solo no sistema de cultivo mínimo, maior produtividade, renda líquida e relação benefício/custo.

\section{REFERÊNCIAS}

AGRIANUAL - ANUÁRIO DA AGRICULTURA BRASILEIRA. São Paulo: FNP, 2013.

AOUN, S. Análise quantitativa de risco de mercado de milho no estado de São Paulo. Informações Econômicas, São Paulo, v.44, n.2, p.23-31, mar./abr. 2014.

ALMEIDA, R.A.S.; TAVARES-SILVA, C.A.; SILVA, S.L. Desempenho energético de um conjunto trator-semeadora em função do escalonamento de marchas e rotações do motor. Revista Agrarian, Dourados, v.3, n.7, p.63-70, 2010.

ANDRADE, C.; ALCÂNTARA, F. A.; MADEIRA, N. R.; SOUZA, R. F. Erosão hídrica em um Latossolo Vermelho cultivado com hortaliças sob diferentes sistemas de manejo. In: Anais... CONGRESSO BRASILEIRO DE CIÊNCIA DO SOLO, 32., 2009.

ANP - AGÊNCIA NACIONAL DO PETRÓLEO, GÁS NATURAL E BIOCOMBUS TÍVEIS. Sistema de levantame nto de preços. 2012. Disponível em:

<http://www.anp.gov.br/preco/prc/Resumo_Mensal_Estado.asp>. Acesso em: ago. 2014.

ASABE - AMERICAN SOCIETY OF AGRICULTURAL AND BIOLOGICAL ENGINEERS. Agricultural machinery management. St. Joseph. ASABE Standards, 2006. (ASAE EP 495.5).

ASAE - AMERICAN SOCIETY OF AGRICULTURAL ENGINEERS. Agricultural machinery manage ment - EP496.2. St. Joseph: ASAE Stand ards, 2002. p.366-371.

BALASTREIRE, L. A. Máquinas agrícolas. 3.ed. São Paulo: Ed. Manole, 2007. 307 p.

BNDES - BANCO NACIONAL DO DESENVOLVIMETO. Circular sup/aoi no 31/2014-

BNDES. Disponível em:

<http://www.bndes.gov.br/SiteBNDES/export/sites/default/bndes_pt/Galerias/Arquivos/produtos/do wnload/circulares/14Cir031_AOI.pdf>. Acesso em: ago. 2014.

BELlÉ, M.; ALONÇO, A. S.; FRANCETTO, T. R.; ROSSATO, F. P.; FRANCK, C. J.; CARPES, D. P. Demanda energética e mobilização do solo com o uso de escarificadores em sistemas de semeadura direta. Revista Brasileira de Engenharia Agrícola e Ambiental, Campina Grande, v.18, n.5, p.551-558, 2014.

CENTENO, A. S.; KAERCHER, D. C usto operacional das máquinas agrícolas. Agrianual, São Paulo, v.15, p.113-116, 2010.

CONAB. Acompanhamento da Safra Brasileira: grãos, safra 2012/2013, nono levantamento, junho 2013. Disponível em: < http://www.conab.gov.br/OlalaCMS/uploads/arquivos/13_06_06_0 9_09_27_boletim_graos_-_junho_2013.pdf>. Acesso em: ago. 2014.

CUNHA, E. Q.; STONE, L. F.; MOREIRA, J. A. A.; FERREIRA, E. P. B.; DIDONET, A. D.; LEANDRO, W. M. Sistemas de preparo do solo e culturas de cobertura na produção orgânica de feijão e milho. I- Atributos físicos do solo. Revista Brasileira de Ciência do Solo, Viçosa, MG, v.35, n.2, p.603-611, 2011. 
DEMARCHI, M. Análise da conjuntura agropecuá ria. 2012. Disponível em: <http://www.agricultura.pr.gov.br/arquivos/File/deral/Prognosticos/milho_2011_12.pdf>. Acesso em: ago. 2014.

EMBRAPA - EMPRES A BRASILEIRA DE PESQUIS A AGROPECUARIA. Centro Nacional de Pesquisas de Solos. Sistema brasileiro de classificação de solos. Brasília, 1999. 412p.

ESPERANCINI, M. S. T.; PAES, A. R.; BICUDO, S. J. Análise de rentabilidade e risco na produção de milho verão, em três sistemas produtivos, na região de Botucatu, estado de São Paulo. Informações Econômicas, São Paulo, v.34, n.8, ago. 2004.

FERNANDES, C. H.; SILVEIRA, J. C. M.; RINALDI, P. C. N. Avaliação do custo energético de diferentes operações agrícolas mecanizadas. Ciência e Agrotecnologia, Lavras, v.32, n.5, p.15821587, set./out., 2008.

FUENTES-LLANILLO, R.; GUIMARÃES, M. de F.; TAVARES FILHO, J. Morfologia e propriedades físicas de solo segundo sistemas de manejo em culturas anuais. Revista Brasileira de Engenharia Agrícola e Ambiental, Campina Grande, v.17, n.5, p.524-530, 2013.

JASPER, S. P.; VELINI, E. D.; SOUZA, S. F. G. Comparação econômica do milho produzido com efeito hormético. Agrarian, Dourados, v.7, n.24, p.348-354, 2014.

LAFLEN, J. M.; AMEMIYA, M.; HINTZ, E. A. Measuring crop residue cover. Journal of Soil and Water Conservation, Ankeny, v.36, p.341- 343, 1981.

MIALHE, L. G. Manual de mecanização agrícola. São Paulo: Agronômica Ceres, 1974. 301p.

MIGUEL, F. B.; ESPERANCINI, M. S. T.; FURLANETO, F. P. B.; BÁRBARO, I. M.; TICELI, M. Adoção de milho transgênico no estado de São Paulo: resultados econômicos e riscos.

Informações Econômicas, São Paulo, v.43, n.6, nov./dez., 2013

MIGUEL, F. B.; ESPERANCINI, M. S. T.; GRIZOTTO, R. K. Rentabilidade e risco da produção de milho safrinha geneticamente modificado e convencional na região de Guaíra/SP. Ene rgia na Agricultura, Botucatu, v.29, n.1, p.64-75, jan.-mar., 2014.

MILAN, M. Gestão sistêmica e plane jamento de máquinas agrícolas. 2004. 100 f. Tese (LivreDocência) - Escola Superior de Agricultura "Luiz de Queiroz", Universidade de São Paulo, Piracicaba, 2004.

MOLIN, J. P.; DIAS, C. T. S.; CARBONERA, L. Estudos com penetrometria: Novos equipamentos e amostragem correta. Revista Brasileira de Ciência do Solo, Viçosa, MG, v.16, n.5, p.584-590, 2012.

PORTELA, J. C.; CINTRA, F. L. D.; CARVALHO, H. W. L.; ANJOS, J. L.; MELO, P. O. Atributos físico-hídricos e químicos de solos sob cultivo de milho na região agreste de Sergipe. Agropecuária Científica no Semiá rido, Campina Grande, v.10, n.1, p.51 - 58, jan.-mar., 2014.

ROCHA, K. F.; CASSOL, L. C.; PIVA, J. T.; MINATO, E. A.; FAVERSANI, J. C. Caracteres morfológicos e componentes de rendimento de milho sob diferentes sistemas de preparo de solo e plantas de cobertura de inverno. Sy nergis mus scyentifica UTFPR, Pato Branco, v.9, n.1, 2014.

SANTOS, G. J.; MARION, J. C.; SEGATTI, S. Administração de custos na agropecuária. 3. ed. São Paulo: Atlas, 2008.

SILVEIRA, G. M. Mecanização: custo horário das máquinas agrícolas. DBO Agrotecnologia, São Paulo, p.26-29, 2005.

STOLF, R.; MURAKAMI, J. H.; MANIERO, M. A.; SILVA, L. C. F.; SOARES, M. R. Incorporação de régua para medida de profundidade no projeto do penetrômetro de impacto Stolf. Revista Brasileira de Ciência do Solo, Viçosa, MG, v.36, n.5, p.1476-1482, 2012.

TIEPPO, R.C.; GABRIEL FILHO, A.; SILVA, S.L. \& GNOATTO, E. Desenvolvimento de um penetrômetro manual eletrônico. Acta Scientiarm. Technology, Maringá, v.33, n.1, p.9-15, 2011. 